\title{
Caracterização física de substratos para plantas
}

\author{
Thais Queiroz Zorzeto $\left({ }^{1 *}\right)$; Sonia Carmela Falci Dechen ( $\left.{ }^{2}\right)$; Mônica Ferreira de Abreu (2); \\ Flávio Fernandes Júnior (3)
}

(') Universidade Estadual de Campinas (UNICAMP), Faculdade de Engenharia Agrícola, Curso de Pós-Graduação em Engenharia Agrícola, Av. Cândido Rondon, 501, 13083-875 Campinas (SP), Brasil.

(2) Instituto Agronômico (IAC), Centro de Pesquisa e Desenvolvimento de Solos e Recursos Ambientais, Av. Barão de Itapura 1481 , 13020-902 Campinas (SP), Brasil.

(3) Embrapa Agrossilvipastoril, Caixa Postal 01,78550-003 Sinop (MT), Brasil.

$\left({ }^{*}\right)$ Autora correspondente: thaisqz@uol.com.br

Recebido: 12/mar./2014; Aceito: 8/maio/2014

\section{Resumo}

A caracterização física de substratos para plantas no Brasil ainda é incipiente, embora, apenas com a definição adequada de métodos confiáveis seja possível padronizar insumos e fornecer as recomendações necessárias aos produtores. Objetivou-se caracterizar fisicamente seis substratos para plantas e comparar métodos prescritos pelo Ministério da Agricultura, Pecuária e Abastecimento brasileiro e pelo Comitê Europeu de Normatização. Os substratos avaliados foram: fibra de coco granulada, dois tipos de casca de pínus, casca de arroz estabilizada e duas misturas (50:50, v:v), uma de casca de arroz com fibra de coco granulada e a segunda de casca de pínus e casca de arroz. O projeto, realizado em 2009, teve delineamento experimental inteiramente casualizado. Os substratos apresentaram diferenças quanto aos atributos físicos: umidade, granulometria, densidade volumétrica, capacidade de retenção de água, densidade de partícula e porosidade, características com as quais se pode inferir sobre sua utilização. Quanto aos parâmetros físicos recomendados em cada um dos métodos, sugere-se: para determinação da umidade da amostra, secagem à temperatura de $65 \pm 5^{\circ} \mathrm{C}$; para granulometria, tempo de 10 min de agitação das peneiras; para densidade volumétrica, método da autocompactação; para capacidade de retenção de água, a base do anel volumétrico da amostra como referência e a adoção da dupla saturação e da pré-tensão em 50 hPa; para determinar a curva de retenção de água dos substratos, os pontos de tensão em 10, 30, 50 e 100 hPa; para caracterização dos substratos quanto à sua origem, inclusão da densidade de partícula pela determinação da matéria orgânica e de cinzas.

Palavras-chave: fibra de coco, casca de arroz, casca de pínus, densidade volumétrica, porosidade, capacidade de retenção de água.

\section{Physical characterization of substrates for plants}

\begin{abstract}
Physical characterization of substrates in Brazil is still incipient and, only with the proper definition of reliable methods, substrates can be standard izedand recommendations can be provided for the producer. The objective was to physically characterize six types of substrates for plants and to compare the methods prescribed by Ministry of Agriculture, Livestock and Supply and by European Committee for Standardization. The six substrates evaluated were: granulated coconut fiber, two types of pinus bark, stabilized rice rusk and two mixtures (50:50, v:v), one of rice rusk with granulated coconut fiber and the second pinus bark with rice husk. The project, realized in 2009, has a completely randomized experimental design. The substrates showed differences as to the physical attributes studied: humidity, particle size distribution, bulk density, water retention capacity, particle density and porosity, characteristics with which one can infer on their use. For the physical parameters for each of the recommended methods are suggested: for the determination of the sample humidity, drying at $65^{\circ} \mathrm{C} \pm 5{ }^{\circ} \mathrm{C}$; for particle size distribution, time of 10 minutes of stirring sieves; for the bulk density, the method of self-compaction; for the water retention capacity, the base of sample ring as reference and the adoption of the double saturation and the pre-tension of $50 \mathrm{hPa}$; for the determination of water retention curve of substrates, the tension points of 10,30, 50 and $100 \mathrm{hPa}$; for the characterization of substrates according to its origin, the inclusion of particle density by the determination of the organic matter and ash.
\end{abstract}

Key words: granulated coconut fiber, rice husk, pinus bark, bulk density, porosity, water retention capacity. 


\section{INTRODUÇÃO}

Substrato para plantas é todo material poroso, usado puro ou em mistura, que, colocado em um recipiente, proporciona ancoragem e suficientes níveis de água e oxigênio para um ótimo desenvolvimento das plantas (Vence, 2008). A caracterização física de substratos é importante para o conhecimento e a padronização dos insumos e, principalmente, para que os produtores possam decidir de forma consciente por sua aquisição e uso, as indústrias possam melhorar a qualidade e o poder público possa fiscalizar a veracidade da informação nas embalagens.

No Brasil, os métodos oficiais para a determinação dos parâmetros físicos em substratos para plantas foram publicados na Instrução Normativa n. ${ }^{\circ} 17$ (IN n. ${ }^{\circ} 17$ ), de 21 de maio de 2007 (BRASIL, 2007), alterada pela Instrução Normativa n. 31 (IN n. ${ }^{\circ} 31$ ), de 23 de outubro de 2008 (BRASIL, 2008). A IN n. 17 traz métodos para análise física e química de substratos para plantas e condicionadores de solos, dentre os quais estáo o da preparação inicial do material e os dos atributos: umidade, densidade e capacidade de retençáo de água. A IN n. ${ }^{\circ} 31$ altera a IN n. ${ }^{\circ} 17$ com relaçáo aos métodos de avaliação de densidade e de capacidade de retenção de água. Os métodos oficiais do Brasil não consideram atributos como granulometria, densidade de partícula e porosidade. As definiçôes e normas sobre as especificaçôes e as garantias, as tolerâncias, o registro, a embalagem e a rotulagem dos substratos para plantas foram publicadas na Instrução Normativa n. ${ }^{\circ} 14$ (IN n. ${ }^{\circ} 14$ ), de 15 de dezembro de 2004 (BRASIL, 2004).

Na Europa, o Comitê Europeu de Normatização (CEN) publicou suas normas para análise e caracterização dos componentes e das misturas de substratos para plantas em 1999 (CEN, 1999b,c). A norma EN 13040 (CEN, 1999b) traz métodos para preparação das amostras para análises físicas e químicas, para determinação do conteúdo de matéria seca, de umidade e da densidade (denominada "densidade aparente compactada em laboratório”). A norma EN 13041 (CEN, 1999c) descreve os métodos para a determinação de densidade aparente com a amostra seca (ou abreviadamente, densidade aparente seca), volume de ar, volume de água, valor de contração e porosidade total. Dentre os atributos discutidos neste trabalho, apenas a granulometria não é considerada nas normas europeias citadas.

Há diversas pesquisas científicas que caracterizam fisicamente tipos de substratos (Cardoso et al., 2010; Fermino e Kämpf, 2006; Pagliarini et al., 2012; Valero et al., 2009; Vieira e Pauletto, 2009), avaliam a utilização de novos materiais como substratos (Daudt et al., 2007; Fermino et al., 2010) ou os estudam com o desenvolvimento de diversas culturas (Fernandes et al., 2006, 2007; Souza Júnior et al., 2011). Entretanto, com relação à avaliação e comparação dos métodos foram poucos os trabalhos encontrados (Abreu et al., 2012; Baumgarten, 2002; Fermino e Kämpf, 2012; Terés et al.,
2001; Wever e van Winkel, 2004). Apenas com a definiçâo adequada de métodos confiáveis será possível a comparação de resultados, a padronização dos insumos e a formulaçáo das recomendaçốes necessárias ao produtor.

As hipóteses do trabalho foram: a) Métodos diferentes para a avaliação de atributos físicos de substratos produzem resultados semelhantes ou comparáveis; b) A partir da caracterização da granulometria de cada substrato é possível inferir seu comportamento físico; c) A adição de substratos com características físicas diferentes altera o substrato original. Com base nas hipóteses, definiram-se os objetivos: a) Comparar métodos de caracterização física de substratos existentes na literatura nacional e internacional e identificar o método mais adequado; b) Analisar atributos físicos de quatro substratos e de duas misturas de substratos para plantas.

\section{MATERIAL E MÉTODOS}

\section{Preparação inicial das amostras}

Para as amostras serem consideradas adequadas aos procedimentos, elas devem passar por uma peneira de malha de 19 x $19 \mathrm{~mm}$ (IN n. ${ }^{\circ} 17$ ) e por uma de 20 × $20 \mathrm{~mm}$ (EN 13040). Caso uma quantidade superior a $10 \%$ fique retida nas peneiras, as amostras são consideradas inadequadas para serem avaliadas por esses métodos. Neste trabalho foi usada a peneira de malha $19 \times 19 \mathrm{~mm}$.

\section{Umidade}

Para a avaliação da umidade dos substratos, testaram-se duas temperaturas de secagem: a $65 \pm 5^{\circ} \mathrm{C}$ (IN n. $\left.{ }^{\circ} 17\right)$ e a $103 \pm 2{ }^{\circ} \mathrm{C}(\mathrm{EN} \mathrm{13040)}$.

\section{Granulometria}

Utilizaram-se peneiras de $12,7 \mathrm{~cm}$ de diâmetro, com malhas de: 3,$35 ; 2,00 ; 1,00 ; 0,50 ; 0,25 ; 0,10$ e $0,06 \mathrm{~mm}$. Uma amostra de $100 \mathrm{~g}$ de substrato seco ao ar foi disposta sobre o jogo de peneiras supracitado, acoplado a um agitador mecânico. Os tempos de agitação foram de 3 minutos e de 10 minutos (Miner, 1994). Após a agitação, a porção de substrato retida em cada peneira foi pesada e os valores utilizados para a determinaçáo da porcentagem sobre a massa da amostra.

\section{Densidade volumétrica}

A densidade volumétrica das amostras na umidade atual foi caracterizada segundo a IN n. ${ }^{\circ} 31$ e a EN 13040. A IN n. 31 descreve o método como de autocompactação, em que uma proveta plástica é preenchida com o substrato na 
umidade atual e é deixada cair sob a ação do seu próprio peso de uma altura de $10 \mathrm{~cm}$, por dez vezes consecutivas. A EN 13040 nomeia a densidade volumétrica como densidade aparente compactada em laboratório e utiliza um cilindro de ensaio totalmente preenchido com o substrato na umidade atual e um peso de $650 \mathrm{~g}$, que é suavemente colocado sobre o material, permanecendo por $180 \pm 10 \mathrm{~s}$. A densidade volumétrica em ambos os métodos é calculada a partir da massa do substrato após a compactação.

A densidade volumétrica das amostras secas foi determinada com a IN n.o 31 e com a EN 13041. A IN n. ${ }^{\circ} 31$ determina o cálculo que considera a umidade atual do substrato e a densidade com a amostra úmida, conforme a equação:

$$
D_{\text {seca }}=D_{\text {úmida }} * \frac{\left(100-U_{\text {atual }}\right)}{100}
$$

onde: $\mathrm{D}_{\text {seca }}=$ densidade volumétrica da amostra seca $\left(\mathrm{kg} \mathrm{m}^{-3}\right)$; $\mathrm{D}_{\text {úmida }}=$ densidade volumétrica da amostra úmida $\left(\mathrm{kg} \mathrm{m}^{-3}\right)$; $\mathrm{U}_{\text {atual }}=$ umidade atual da amostra (\%).

A norma europeia EN 13041 denomina a densidade volumétrica da amostra seca como densidade aparente seca. O método está vinculado à determinação da capacidade de retenção de água do substrato e em seu cálculo estão incluídas variáveis como massa da amostra seca (após submissão à tensão de $10 \mathrm{hPa}$ ) e volume do anel da amostra.

\section{Capacidade de retenção de água}

A capacidade de retenção de água foi avaliada pela IN n. ${ }^{\circ} 31$ e pela EN 13041 . Segundo a IN n. ${ }^{\circ} 31$, em um anel volumétrico $(100 \pm 5 \mathrm{~mm}$ de diâmetro interno e $50 \pm 1 \mathrm{~mm}$ de altura) é disposto o substrato, cuja massa é calculada pela densidade volumétrica (IN n. ${ }^{\circ} 17$ ) e pelo volume do anel. Os substratos são saturados, por $24 \mathrm{~h}$, e colocados sobre uma mesa de tensão ajustada para $10 \mathrm{~cm}$ de coluna de água $(10 \mathrm{hPa})$, onde permanecem por cerca de $48 \mathrm{~h}$. Após esse tempo, as amostras sáo retiradas, pesadas e secas em estufa a $65^{\circ} \mathrm{C}$ (por cerca de $48 \mathrm{~h}$ ) até massa constante. Como na IN n. ${ }^{\circ} 31$ não há referência para o ajuste da tensão, se medida a partir da base ou da metade da altura do anel, avaliaram-se também esses dois itens.

A EN 13041 baseia-se em saturar uma amostra com água e equilibrá-la, primeiramente, em uma tensão de $50 \mathrm{~cm}$ de coluna d'água ( $50 \mathrm{hPa}$ ) em leito de areia. A seguir, as amostras são transferidas para cilindros formados por dois anéis sobrepostos $(100 \pm 5 \mathrm{~mm}$ de diâmetro interno e $50 \pm 1 \mathrm{~mm}$ de altura cada um), novamente saturadas com água e equilibradas na tensão de $10 \mathrm{~cm}$ de coluna d'água $(10 \mathrm{hPa})$, medida a partir da metade da altura do anel inferior. Uma vez alcançado o equilíbrio, o anel inferior será considerado para a análise, após secagem em estufa a $103 \pm 2{ }^{\circ} \mathrm{C}$. Os atributos físicos (densidade aparente seca, utilizada também para o cálculo da porosidade, e volume de água) são calculados a partir da massa das amostras secas e úmidas do anel inferior, de acordo com a norma.

Apenas com o ponto $10 \mathrm{hPa}$ de tensão é possível determinar o espaço de aeração (EA) de um substrato, ou seja, a proporção de volume de substrato que contém ar depois de saturado com água e drenado a $10 \mathrm{hPa}$ de tensão. No entanto, não é possível determinar outras características importantes relacionadas à sua capacidade de retenção de água, como a água facilmente disponível (AFD) (correspondente à água liberada pelo substrato ao passar de $10 \mathrm{a} 50 \mathrm{hPa}$ ) e a água tamponante (AT) (liberada pelo substrato ao passar de 50 a $100 \mathrm{hPa}$ ). Portanto, além do ponto $10 \mathrm{hPa}$ de tensão, determinaram-se também outros, como 30, 50, 60 e $100 \mathrm{hPa}$, seguindo-se o mesmo método da EN 13041.

\section{Densidade de partícula}

Expressa a relação entre a massa de material seco e o volume real ocupado por essas partículas, não incluindo-se o espaço ocupado pelos poros. Portanto, essa característica não é afetada pela granulometria dos substratos, mas pela composição de suas partículas. Apesar de as normas brasileiras não a incluírem em seus métodos, a IN n. ${ }^{\circ} 14$ determina que os substratos sejam caracterizados quanto à origem de suas matérias-primas como minerais, orgânicos, sintéticos ou mistos. Em solos, a densidade de partículas é importante para se conhecer sua composição: se o solo apresentar grandes quantidades de minerais mais pesados, como a magnetita, sua densidade de partícula será elevada; se, ao contrário, apresentar maior quantidade de matéria orgânica, mais leve, portanto, sua densidade de partículas será menor. Da mesma forma, a densidade de partículas permite separar um substrato à base orgânica de um à base mineral. Como referência para substratos, considera-se que partículas minerais apresentam densidade de partícula de $2,65 \mathrm{~g} \mathrm{~cm}^{-3}$ e as de matéria orgânica, de $1,45 \mathrm{~g} \mathrm{~cm}^{-3}$ (Martinez, 2002; Rowell, 1994).

A densidade de partículas foi avaliada pela EN 13041 e por Miner (1994). Para o cálculo desse atributo, a EN 13041 considera o conteúdo de matéria orgânica e de cinzas, cuja determinação foi baseada na norma EN 13039 (CEN, 1999a), que estabelece a secagem da amostra, em estufa, a $103 \pm 2{ }^{\circ} \mathrm{C}$, para quantificar o conteúdo de matéria orgânica, e na mufla, a $450 \pm 10{ }^{\circ} \mathrm{C}$, para o conteúdo de cinzas.

Miner (1994) utiliza picnômetros preenchidos, primeiramente, com substrato seco a $103 \pm 2{ }^{\circ} \mathrm{C}$ durante $24 \mathrm{~h}$, até cerca de um terço do seu volume. Acrescenta-se água destilada e fervida até metade do volume do picnômetro e, depois de deixar em repouso durante $24 \mathrm{~h}$, ferve-se o conteúdo. Esfria-se em banho termostático a $20{ }^{\circ} \mathrm{C}$ e completa-se o volume com água destilada, também previamente fervida e resfriada a $20^{\circ} \mathrm{C}$. Na sequência, realiza-se o mesmo processo somente com água destilada. 


\section{Porosidade}

A porosidade está relacionada à limitaçáo do volume para o crescimento de plantas em recipientes, sendo o valor de $85 \%\left(0,85 \mathrm{~m}^{3} \mathrm{~m}^{-3}\right)$ tido como referência (De Boodt e Verdonck, 1972). Tais poros serão responsáveis pelas trocas gasosas, determinarão a movimentaçáo de água no recipiente e o padrão de drenagem que se estabelecerá.

A porosidade total dos substratos foi calculada segundo a EN 13041 com a equaçáo que utiliza valores da densidade aparente com a amostra seca (EN 13041) e da densidade de partícula. A IN n. ${ }^{\circ} 17$ não determina método para avaliaçáo da porosidade de substratos.

$$
P_{t}=\frac{\left(1-D_{\text {aparenteseca }}\right)}{D_{\text {particula }}} * 100
$$

onde: $\mathrm{P}_{\mathrm{t}}=$ Porosidade do substrato $\left(\% \mathrm{v} \mathrm{v}^{-1}\right) ; \mathrm{D}$ aparenteseca $=$ densidade aparente da amostra seca $\left(\mathrm{kg} \mathrm{m}^{-3}\right)$; $\mathrm{D}$ partícula $=$ densidade de partícula $\left(\mathrm{kg} \mathrm{m}^{-3}\right)$.

\section{Delineamento experimental}

O delineamento experimental foi inteiramente casualizado em esquema fatorial, com 12 tratamentos, sendo seis substratos (fibra de coco granulada, da empresa Amafibra, analisada na forma como recebida na embalagem; dois tipos de casca de pínus, das empresas Lupa Fertilizantes e Vida Verde; casca de arroz pura - usada experimentalmente como componente e como testemunha - proveniente de um produtor e mantida em local protegido no campo, em chão cimentado, durante 12 meses, para estabilizaçáo; e duas misturas em proporçôes de $50 \%$, uma de casca de arroz com fibra de coco granulada e a segunda de cascas de pínus e de arroz), dois métodos de caracterização para cada atributo e cinco repetiçôes. Foi realizada a análise de variância e, quando significativa, as médias foram comparadas pelo teste de Tukey $(\mathrm{p}>0,05)$.

\section{RESULTADOS E DISCUSSÃO}

\section{Comparação entre métodos}

\section{Umidade}

A comparação entre as duas temperaturas analisadas não mostrou diferenças significativas para a obtenção da umidade em todos os substratos avaliados (figura 1). Para a secagem do material à temperatura de $103^{\circ} \mathrm{C}$, líquidos voláteis distintos da água podem ocorrer na matéria orgânica e advirem oxidaçóes ou decomposiçóes que modifiquem a medida, além de eventuais perdas por queima de material orgânico (Burés, 1997). Assim, muitos laboratórios secam substratos orgânicos a $65^{\circ} \mathrm{C}$, como recomenda a instrução normativa brasileira, com base em temperatura de secagem de tecidos vegetais (Tedesco et al., 1985).

\section{Granulometria}

Os tempos de agitação (3 e 10 minutos) causaram diferenças nas porcentagens retidas em cada peneira (figura 2). Nemati et al. (2009) definem a duração de peneiramento como uma das possíveis variáveis que afetam a medição da granulometria.

Para a fibra de coco granulada, essa observaçáo pode ser vista de forma significativa na fraçáo intermediária e em parte da fina. Para ambas as cascas de pínus, o comportamento foi semelhante, sendo que o tempo de agitação interferiu significativamente apenas na fração fina de ambos os

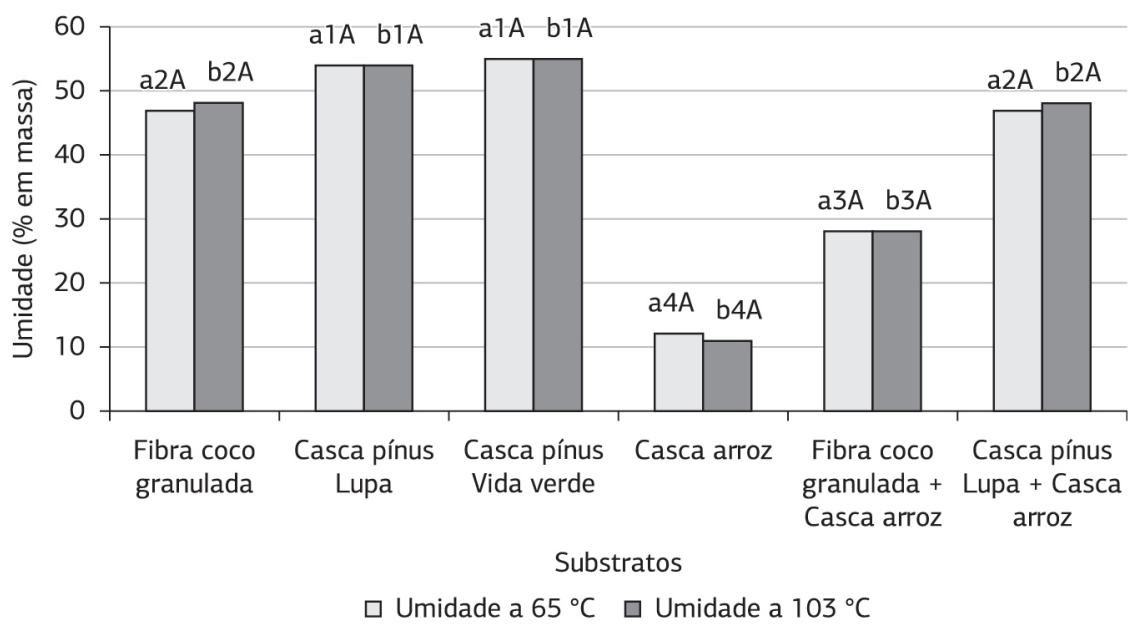

Figura 1. Umidade relativa de substratos após secagem a $65^{\circ} \mathrm{C}$ e a $103^{\circ} \mathrm{C}$. Letras minúsculas com índices comparam substratos diferentes e letras maiúsculas, temperaturas para mesmos substratos; mesmos índices ou mesmas letras náo diferem entre si pelo teste de Tukey a 5\% de significância. 

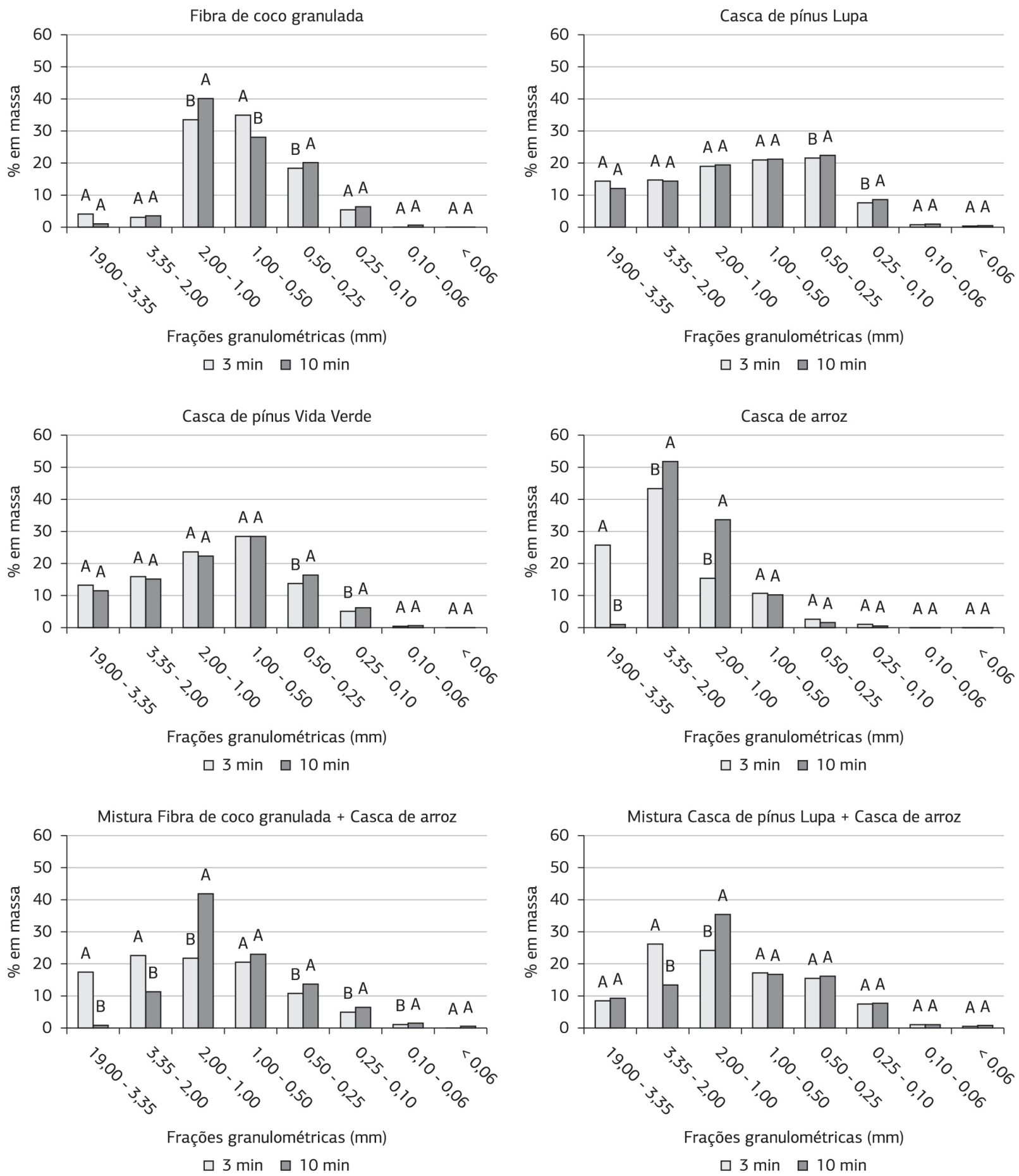

Figura 2. Análise granulométrica de substratos com tempos de agitação de peneiras de 3 e de 10 minutos. Letras maiúsculas comparam tempos de agitação para mesmos substratos pelo teste de Tukey a 5\% de significância.

substratos. Para a casca de arroz e para as suas misturas com fibra de coco granulada e com casca de pínus Lupa, nas fraçóes de maior abertura das peneiras, devido ao formato longitudinal da casca de arroz, ocorre um rearranjo das partículas durante o maior tempo de agitação, deslocando-as para as peneiras de malhas inferiores. Portanto, o maior tempo de agitação (10 $\mathrm{min})$ apresentou melhores resultados, pois permitiu a melhor acomodação das partículas, de forma que elas se rearranjassem e passassem para as peneiras inferiores de menor abertura.

\section{Densidade volumétrica}

A tabela 1 traz valores de densidade volumétrica, segundo a IN n.o 31 (substratos úmidos e secos) e segundo a EN 13040 (substratos úmidos) e a EN 13041 (substratos secos). 
Tabela 1. Densidade volumétrica dos substratos úmidos e secos determinada pela instrução normativa brasileira e pela norma europeia

\begin{tabular}{|c|c|c|c|c|}
\hline \multirow{4}{*}{ Substrato } & \multicolumn{4}{|c|}{ Densidadevolumétrica } \\
\hline & \multicolumn{2}{|c|}{ Substrato úmido } & \multicolumn{2}{|c|}{ Substrato seco } \\
\hline & IN n. 31 & EN 13040 & IN n. 31 & EN 13041 \\
\hline & \multicolumn{4}{|c|}{ 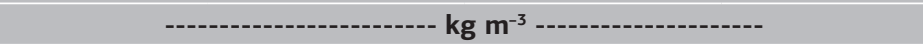 } \\
\hline Fibra de coco granulada & 173,94 a2A & $154,50 \mathrm{~b} 2 \mathrm{~B}$ & 92,16 a1 $\mathrm{A}$ & $95,50 \mathrm{~b} 1 \mathrm{~A}$ \\
\hline Casca de pínus Lupa & 726,85 a5A & 594,33 b5B & 336,36 a6A & 352,31 b5B \\
\hline Casca de pínus Vida Verde & 602,11 a4A & $484,41 \mathrm{~b} 4 \mathrm{~B}$ & 270,97 a5A & 295,85 b4B \\
\hline Casca de arroz & 141,32 a $1 \mathrm{~A}$ & $126,23 \mathrm{~b} 1 \mathrm{~B}$ & 124,85 a3A & 115,03 b2B \\
\hline Fibra de coco granulada + casca de arroz & 163,30 a2A & 146,36 b2B & 117,85 a2A & $113,53 \mathrm{~b} 2 \mathrm{~A}$ \\
\hline Casca de pínus Lupa + casca de arroz & 434,03 a3A & 389,92 b3B & 229,17 a $4 \mathrm{~A}$ & 243,14 b3B \\
\hline
\end{tabular}

Letras minúsculas com índices comparam substratos diferentes para mesmos métodos; e letras maiúsculas, métodos e separadamente para substrato úmido e substrato seco, para mesmos substratos; mesmos índices ou mesmas letras não diferem entre si pelo teste de Tukey a 5\% de significância.

Para a determinação da densidade volumétrica, concorda-se com Fermino e Kämpf (2012) na afirmaçáo de que há dificuldade na interpretação de laudos emitidos por laboratórios de análise física de substratos, pois os métodos utilizados não são padronizados. Com relação aos métodos, houve diferença significativa nos resultados das densidades volumétricas encontradas, sendo os maiores valores de densidade volumétrica obtidos pelo método da IN n.o 31 (tabela 1).

As principais diferenças entre os métodos consistem na forma com que os recipientes de ensaio sáo preenchidos e a compactação é realizada. No caso da IN n. ${ }^{\circ} 31$, a recomendação é evitar a formação de poros artificiais ao colocar o substrato na proveta, sendo que depende do avaliador a forma como a amostra é colocada, se mais sutil ou bruscamente; na EN 13040 é utilizada uma peneira disposta sobre um funil e a amostra, ao ser peneirada, cai diretamente dentro do cilindro de ensaio, o que reduz a dependência do avaliador. Entretanto é possível orientar o avaliador mediante treinamento para a realização das análises.

A forma de compactação das amostras também difere de um método para o outro: pela IN n. ${ }^{\circ} 31$, é realizado pela autocompactação; pela EN 13040, com um peso de $650 \mathrm{~g}$ sobre o material. Pela IN n.o 31, a compactação é realizada pelo próprio avaliador, deixando cair a proveta sob a ação de seu próprio peso por dez vezes consecutivas - nem todas as vezes a proveta cairá sobre a superfície de trabalho da mesma forma, como deveria, podendo titubear sobre seu próprio eixo ou cair de maneira precisa, o que poderá alterar a compactaçáo e a leitura do volume ocupado pelas partículas na proveta. Assim, ao escolher os anéis para servirem de guia, eles devem ter diâmetro apenas um pouco maior que o da proveta. Entretanto, De Kreij et al. (2001) mostraram que a utilização de um peso externo para a compressão de um volume definido de substrato pode gerar problemas com substratos fibrosos ou com partículas muito grandes. Apesar de Miner (1994) ter afirmado que a compressão devida à aplicaçáo do peso de $650 \mathrm{~g}$ sobre o substrato é semelhante àquela experimentada pelo substrato pela ação de seu próprio peso, Baumgarten (2002) e De Kreij et al. (2001) afirmam que apenas $75 \%$ da densidade volumétrica determinada pelo método da autocompactaçáo pode ser obtida pela compressão de um peso externo devido à compactaçáo não ser uniforme por todo o volume do cilindro de ensaio. Fermino e Kämpf (2012) observaram que as densidades volumétricas obtidas pela EN 13040 foram 16\%, 29\% e 27\% menores do que as obtidas pela IN n. ${ }^{\circ} 31$ com umidades de $0,62 \mathrm{~g} \mathrm{~g}^{-1}, 0,69 \mathrm{~g} \mathrm{~g}^{-1}$ e $0,72 \mathrm{~g} \mathrm{~g}^{-1}$, respectivamente. Com os substratos em análise, em média, a densidade volumétrica obtida pelo método da EN 13040 representou $87 \%$ da determinada pela IN n. ${ }^{\circ}$ 31. Portanto, para a avaliação da densidade volumétrica, o método da IN n. ${ }^{\circ} 31$ (autocompactaçáa) mostrou-se mais simples e prático, enquanto que o método da EN 13040 é mais demorado e limitado. Wever e van Winkel (2004) também encontraram dificuldades na determinação da densidade volumétrica baseando-se na EN 13040.

Fermino e Kämpf (2005) indicaram que o método da EN 13040, com compactação no topo da amostra, avaliado com amostras muito úmidas $(73 \%$ de umidade gravimétrica) de turfa marrom, mostrou-se mais adequado para preenchimento de recipientes rasos, como bandejas para mudas. Por outro lado, as autoras indicaram que o método de autocompactação, descrito por Hoffmann (1970) e utilizado pela União das Entidades Alemãs de Pesquisas Agrícolas (VDLUFA) para análise de substratos hortícolas (Röber e Schaller, 1985 apud Fermino e Kämpf, 2012), é mais apropriado para recipientes mais altos, em que a compactaçáo inicial pode prevenir a redução do volume do substrato após preenchimento do recipiente.

As densidades volumétricas obtidas para os substratos secos (tabela 1) também apresentaram diferenças significativas para ambos os métodos avaliados (IN n. ${ }^{\circ} 31$ e EN 13041), com exceção dos substratos fibra de coco granulada e de sua mistura com a casca de arroz. Pela IN n. ${ }^{\circ} 31$, a densidade volumétrica foi calculada considerando a densidade volumétrica obtida a partir da amostra úmida e a umidade atual dessa amostra. Pela EN 13041, as amostras são saturadas e submetidas a uma tensão de $50 \mathrm{hPa}$ para homogeneizaçáo da umidade inicial, dispostas em um conjunto de anel duplo, saturadas novamente e submetidas a uma tensão de $10 \mathrm{hPa}$. Depois 
de aplicada essa tensão, observou-se uma redução do volume das amostras, devido à acomodação das partículas e, por esse motivo, observa-se que os maiores valores de densidade volumétrica da amostra seca foram obtidos pelo método da EN 13041.

De fato, o método da autocompactação (IN n.o 31) é mais simples, rápido e prático, enquanto o método da em 13040 é mais demorado e limitado para uso em rotinas de laboratório, como também observaram Baumgarten (2002) e Fermino e Kämpf (2012).

\section{Capacidade de retenção de água - CRA}

Uma das diferenças entre os métodos avaliados consiste no referencial adotado para o ajuste da tensão a ser submetida: a IN n. ${ }^{\circ} 31$ não estabelece nenhum referencial, se em relação à base do anel ou à metade da altura dele; a EN 13041 determina que a pré-tensão seja medida a partir da base do cilindro e que a tensão seja medida a partir da metade da altura do anel inferior. Não houve diferença significativa entre as referências para o ajuste da tensão (tabela 2), sendo possível sua determinação tanto a partir da base do anel volumétrico quanto a partir de seu centro. Entretanto, recomenda-se que a referência adotada seja a partir da base do anel volumétrico da amostra, pela facilidade de execuçáo e pela maior exatidão no ajuste desse ponto.

Tanto a IN n.o 31 quanto a EN 13041 recomendam a determinação da capacidade de retenção de água para o ponto $10 \mathrm{hPa}$ de tensão. A comparação dos métodos para esse ponto, com ajuste da tensão com referência à base do anel volumétrico, mostra que houve diferenças significativas entre os métodos para todos os substratos (figura 3). A EN 13041 estabelece como princípio saturar previamente a amostra com água e pré-equilibrá-la a uma tensão de $50 \mathrm{hPa}$ em um leito de areia; depois de atingido o equilíbrio, saturar novamente a amostra e então submetê-la à tensão de 10 $\mathrm{hPa}$. Por esse método ocorre uma saturação mais completa e homogênea das partículas das amostras e, portanto, observou-se que a porcentagem de água em massa retida no ponto $10 \mathrm{hPa}$ de tensão é superior àquela determinada pelo método da IN n.o 31 . O valor mais baixo obtido pela saturação simples é devido ao volume maior não ocupado por água, consequência da menor eficiência de substituição de ar por água nos poros durante o processo de saturação (Terés et al., 2001).

Observa-se também que o ponto $60 \mathrm{hPa}$ de tensão poderia ser excluído das análises sem muita alteração dos gráficos (figura 4). Entretanto, a tensão de $30 \mathrm{hPa}$ é necessária, já

Tabela 2. Capacidade de retenção de água (CRA) de substratos medida a partir da base e do centro do anel volumétrico

\begin{tabular}{|c|c|c|}
\hline \multirow{3}{*}{ Substratos } & \multicolumn{2}{|c|}{ CRA } \\
\hline & Centro do anel & Base do anel \\
\hline & \multicolumn{2}{|c|}{---- \% (em massa) ------ } \\
\hline Casca de pínus Lupa & 55 a3A & 58 b3A \\
\hline Casca de pínus Vida Verde & 49 a3A & 52 b3A \\
\hline Casca de arroz & 12 a1A & 13 b1 A \\
\hline Fibra de coco granulada + casca de arroz & 39 a2A & 36 b2A \\
\hline Casca de pínus Lupa + casca de arroz & 35 a $2 A$ & 36 b2A \\
\hline
\end{tabular}

Letras minúsculas com índices comparam substratos diferentes e letras maiúsculas, alturas para mesmos substratos; mesmos índices ou mesmas letras não diferem entre si pelo teste de Tukey a $5 \%$ de significância.

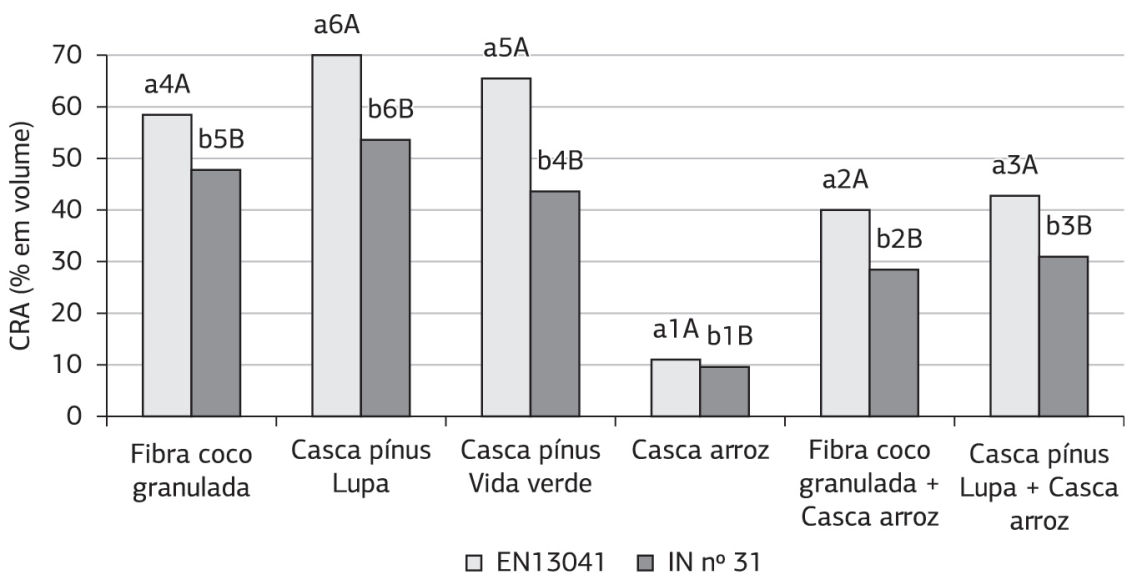

Figura 3. Capacidade de retenção de água (CRA) de substratos na tensão de $10 \mathrm{hPa}$ determinada pelos métodos da instrução normativa brasileira e da norma europeia. Letras minúsculas com índices comparam substratos diferentes e letras maiúsculas, métodos para mesmos substratos; mesmos índices ou mesmas letras não diferem entre si pelo teste de Tukey a 5\% de significância. 
que representa um ponto de inflexáo do gráfico (figura 4), caracterizando a capacidade de retenção de água dos substratos de forma mais detalhada.

\section{Densidade de partícula}

Houve diferença entre os métodos avaliados (tabela 3), sendo o cálculo descrito pela norma EN 13041 o que apresentou os maiores valores. De acordo com a determinação da IN n. ${ }^{\circ} 14$ para a caracterização dos substratos conforme a sua origem, torna-se necessária a inclusão da densidade de partícula nas normas brasileiras, atributo que relaciona o substrato à sua composição. Os métodos avaliados, significativamente diferentes entre si, possuem suas particularidades e dificuldades de execução: pela EN 13041, apesar de ser necessária a determinação das quantidades de matéria orgânica e de cinzas do substrato, a execução é mais simples.

\section{Comparação entre substratos}

\section{Umidade}

As maiores umidades foram encontradas para ambos os substratos de casca de pínus (acima de 50\% em massa) e fibra de coco granulada (média de $47 \%$ em massa) (figura 1). A casca de arroz apresentou a menor umidade (média de $12 \%$ em massa) e, quando presente na mistura, tanto com a fibra de coco granulada quanto com a casca de pínus Lupa, reduziu a umidade nessas amostras.

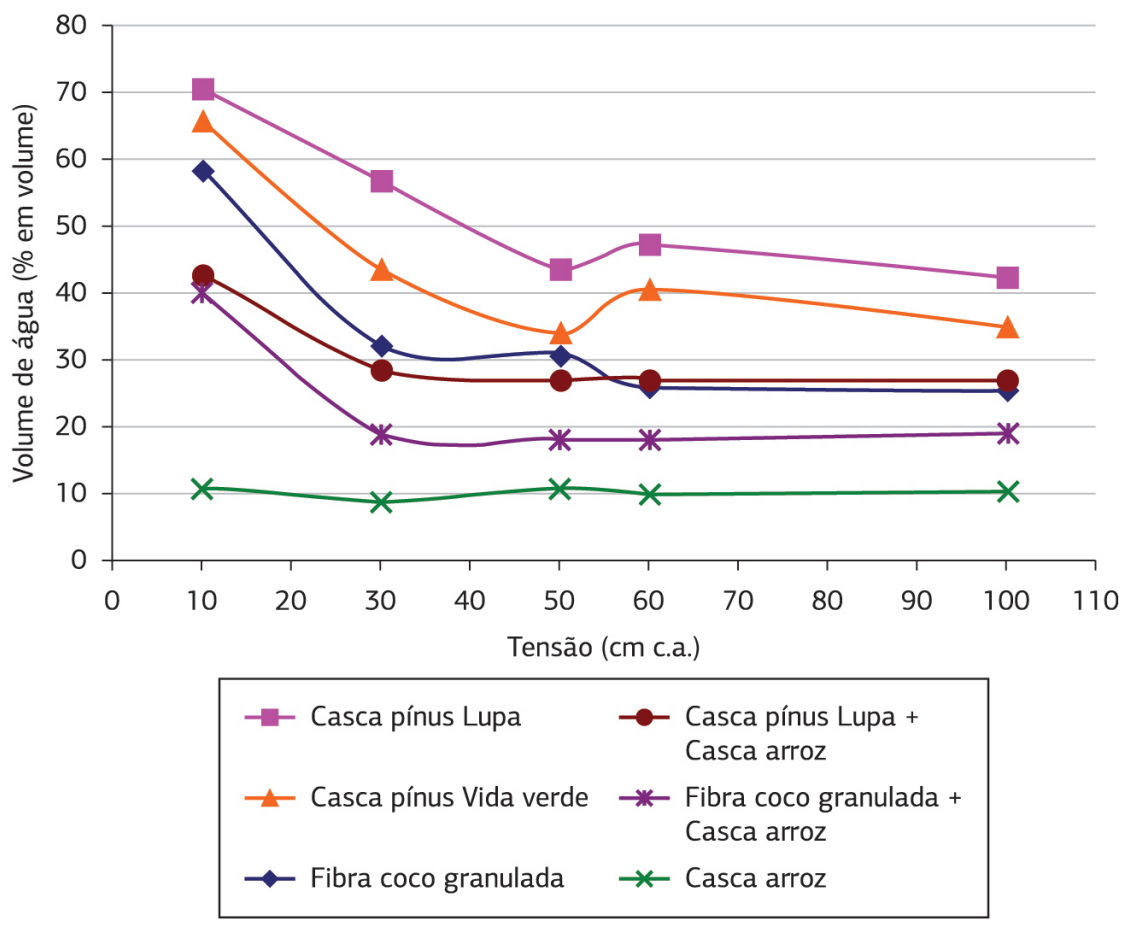

Figura 4. Curva de retenção de água para substratos submetidos às tensóes de 10, 30, 50, 60 e $100 \mathrm{hPa}$.

Tabela 3. Densidade de partículas de substratos determinada pelos métodos da norma europeia e de Miner (1994)

\begin{tabular}{|c|c|c|c|c|}
\hline \multirow{3}{*}{$\begin{array}{l}\text { Substrato } \\
\text { Fibra de coco granulada }\end{array}$} & \multirow{2}{*}{\multicolumn{2}{|c|}{$\begin{array}{c}\text { EN } 13041 \\
\mathrm{~g} \mathrm{~cm}^{-3}\end{array}$}} & \multirow{2}{*}{\multicolumn{2}{|c|}{$\begin{array}{c}\text { Miner (1994) } \\
\mathrm{g} \mathrm{cm}^{-3}\end{array}$}} \\
\hline & & & & \\
\hline & 1,74 & a1A & 1,55 & b1B \\
\hline Casca de pínus Lupa & 2,04 & $\mathrm{a} 2 \mathrm{~A}$ & 1,95 & $\mathrm{~b} 2 \mathrm{~A}$ \\
\hline Casca de pínus Vida Verde & 2,03 & $\mathrm{a} 2 \mathrm{~A}$ & 1,81 & $\mathrm{~b} 2 \mathrm{~B}$ \\
\hline Casca de arroz & 2,46 & a3A & 1,60 & b1B \\
\hline Fibra de coco granulada + casca de arroz & 2,00 & $\mathrm{a} 2 \mathrm{~A}$ & 1,60 & b1B \\
\hline Casca de pínus Lupa + casca de arroz & 2,07 & $\mathrm{a} 2 \mathrm{~A}$ & 1,91 & $\mathrm{~b} 2 \mathrm{~B}$ \\
\hline
\end{tabular}

Letras minúsculas com índices comparam substratos diferentes e letras maiúsculas, métodos para mesmos substratos; mesmos índices ou mesmas letras năo diferem entre si pelo teste de Tukey a 5\% de significância. 


\section{Granulometria}

Pode-se sugerir uma classificação para a distribuição granulométrica da seguinte forma: são fraçôes muito grandes as acima de $3,35 \mathrm{~mm}$; grandes as entre 3,35 e $2,00 \mathrm{~mm}$; intermediárias as entre 2,00 e $0,50 \mathrm{~mm}$; finas as entre 0,50 e $0,10 \mathrm{~mm}$; e muito finas as menores do que $0,10 \mathrm{~mm}$.

Os substratos avaliados apresentaram granulometrias distintas (figura 2) e, consequentemente, diferentes proporçóes entre macro e microporosidade, o que influencia diretamente a disponibilidade de água e de ar nos substratos, fato também observado por Mota et al. (2007) e Verdonck e Demeyer (2004).

Para a fibra de coco granulada, houve predominância de fraçôes intermediárias e finas, o que pode ser adequado quando se buscam alta porosidade e presença de microporos, responsáveis pela boa aeração e pela retenção de água no ambiente. Para ambas as cascas de pínus, a distribuição foi uniforme, com fraçôes muito grandes, grandes, intermediárias e finas, o que pode ser prejudicial pela acomodação das partículas menores entre as maiores, diminuindo a porosidade do material devido à sua cimentação. Para a casca de arroz houve predominância de fraçôes muito grandes, grandes e intermediárias, o que favorece a aeração do ambiente radicular mas pode prejudicar a retenção de água do material pela ausência de microporos responsáveis por essa função. Por isso é utilizada quase que exclusivamente como componente para aumentar o espaço de aeração ou para enraizamento de estacas sob nebulização.

\section{Densidade volumétrica}

Para as amostras úmidas, em ambos os métodos, os substratos apresentaram comportamentos semelhantes (tabela 1): valores menores foram encontrados para a casca de arroz $\left(141,32 \mathrm{~kg} \mathrm{~m}^{-3}\right)$, seguida da sua mistura com a fibra de coco granulada $\left(163,30 \mathrm{~kg} \mathrm{~m}^{-3}\right)$ e dessa em sua forma pura $\left(173,94 \mathrm{~kg} \mathrm{~m}^{-3}\right)$. Como a casca de arroz e a fibra de coco granulada possuem valores de densidade muito semelhantes, sua mistura não apresentou diferenças significativas para esse atributo. Os maiores valores foram observados para a mistura da casca de pínus Lupa com casca de arroz $\left(434,03 \mathrm{~kg} \mathrm{~m}^{-3}\right)$, seguida de ambas as cascas de pínus puras $\left(602,11 \mathrm{~kg} \mathrm{~m}^{-3}\right.$ e 726,85 $\left.\mathrm{kg} \mathrm{m}^{-3}\right)$. Nota-se, portanto, que para a casca de pínus Lupa, a adição de casca de arroz em 50\% de volume reduziu significativamente a densidade volumétrica do substrato.

\section{Capacidade de retenção de água - CRA}

Observa-se que no ponto de menor tensão (figura 4), ambos os substratos de casca de pínus e a fibra de coco granulada são os que possuem maior porcentagem de volume de água. A casca de arroz apresentou a menor retenção de água e na forma de mistura, tanto com a fibra de coco granulada quanto com a casca de pínus Lupa, reduzindo a retenção de água desses materiais.

$\mathrm{Na}$ curva de retenção de água dos substratos (figura 4), observa-se que a casca de pínus Lupa apresentou a maior capacidade de retenção de água em todos os pontos avaliados, seguida da casca de pínus Vida Verde e da fibra de coco granulada. Ambas as misturas de fibra de coco granulada e de casca de pínus Lupa tiveram sua capacidade de retençáo de água reduzida devido ao acréscimo de casca de arroz, que apresenta mínima capacidade de retenção de água.

A figura 5 traz informaçóes sobre as características dos substratos quanto ao espaço de aeração (EA), à água facilmente disponível (AFD) e à água tamponante (AT). Os valores referenciais sugeridos em literatura para o espaço de aeração situam-se entre $20 \%$ e $40 \%$ do volume (De Boodt e Verdonck, 1972). Valores elevados do espaço de aeração (EA) como os apresentados pela casca de arroz e pela sua mistura com os outros substratos podem ocasionar deficiências hídricas para as plantas, principalmente com irrigaçóes pouco frequentes. Os substratos de fibra de coco granulada

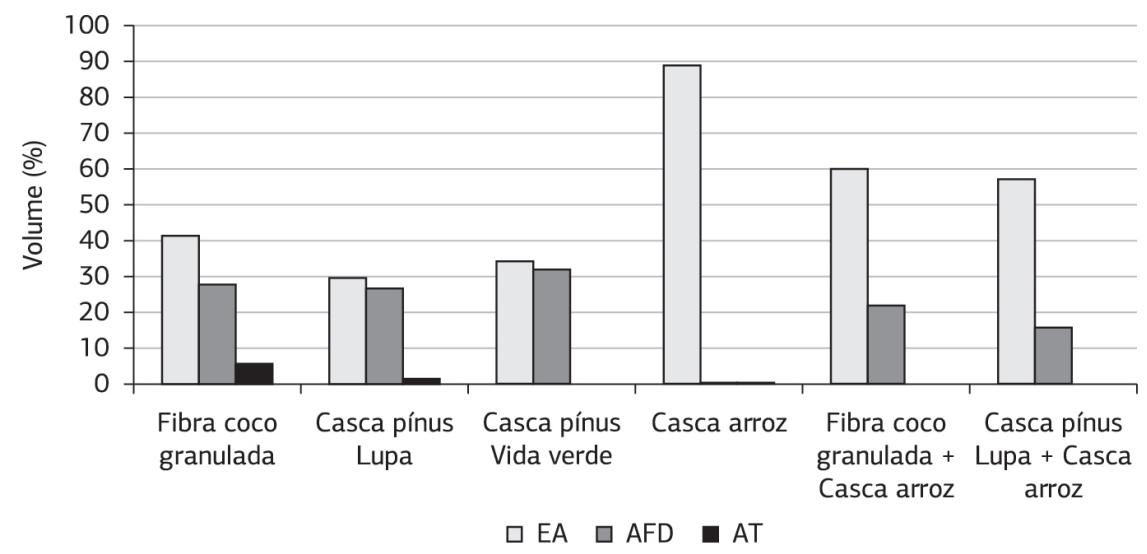

Figura 5. Espaço de aeração (EA), água facilmente disponível (AFD) e água tamponante (AT) para substratos determinados pela norma europeia. 
e ambos os de casca de pínus apresentaram valores dentro da faixa recomendada (figura 5). Valores reduzidos poderiam causar falta de oxigênio para o desenvolvimento das raízes (Allaire et al., 2004). Para a água facilmente disponível (AFD), o valor ótimo situa-se entre 20 e $30 \%$ do volume (Cadahia, 1998). O substrato mais crítico foi a casca de arroz, cujo valor nulo pode inibir o crescimento vegetal na falta de irrigaçóes frequentes. A água tamponante (AT) possui nível ótimo entre $4 \%$ e $10 \%$ em volume (Cadahia, 1998), para o qual apenas a fibra de coco granulada mostrou-se adequada, garantindo à cultura uma certa quantidade de água para seu desenvolvimento mesmo em condições mais limitantes. Essa característica, entretanto, não é aproveitada em cultivos comerciais, visto que, no ponto da AT, as plantas já estariam em estresse hídrico.

\section{Densidade de partícula}

Os substratos mais pesados foram aqueles à base de casca de pínus, na forma pura ou em misturas (tabela 3).

\section{Porosidade}

Observa-se (figura 6) que ambas as cascas de pínus apresentaram baixa porosidade e que, embora a casca de arroz tenha aumentado a quantidade de frações maiores na mistura com a casca de pínus Lupa, esse aumento não foi suficiente para diferir significativamente da baixa porosidade do substrato puro (porque, para a mesma porosidade, as relaçóes entre ar - EA - e água - AFD - podem ser diferentes), apresentando um valor muito aquém do ideal teórico. Tanto a fibra de coco granulada quanto a casca de arroz apresentaram porosidade elevada, com valores acima de 50\%. Berjón e Murray (1998) afirmaram que quando se mesclam materiais com granulometrias distintas, aquele com partículas menores ocupa os espaços vazios existentes entre as partículas maiores do outro material, reduzindo sua porosidade total. Apesar disso, na proporção de mistura utilizada, o aumento das fraçôes maiores devidas à casca de arroz não foi suficiente para alterar significativamente a porosidade da fibra de coco granulada, o que pode ser favorável pela possibilidade de diminuição de custos com os insumos. A mistura de materiais pode resultar em mudanças nas propriedades.

A porosidade total de um substrato pode, em geral, correlacionar-se de maneira inversa com a densidade volumétrica, do mesmo modo que em solos (Vence, 2008). Observou-se essa correlação: os substratos que apresentaram menores valores de porosidade (figura 6) também apresentaram maiores valores de densidade volumétrica (tabela 1) e viceversa.

\section{CONSIDERAÇÕES GERAIS}

Substratos com granulometria distribuída uniformemente entre as fraçôes apresentam maior retenção de água. A distribuição granulométrica uniforme pode conferir, para ambas as cascas de pínus, características não desejáveis, como o aumento da densidade volumétrica e a diminuiçáo da porosidade devido à acomodação de partículas menores entre as maiores. Apesar dos adequados valores de espaço de aeração, o manejo desse substrato deve ser realizado com cautela, pois a baixa porosidade aliada à alta capacidade de retenção de água podem trazer problemas como falta de oxigênio para o desenvolvimento das raízes, para a movimentação de água e para a drenagem.

A casca de arroz possui predominância de fraçóes granulométricas muito grandes, grandes e intermediárias, o que reduz a sua densidade volumétrica, torna elevados a porosidade e o espaço de aeraçáo do ambiente radicular, que podem prejudicar a retenção de água pelo material. Embora esse substrato seja o mais crítico para a água facilmente disponível, cujo valor nulo pode inibir o crescimento vegetal na falta de irrigaçóes frequentes e ocasionar deficiências hídricas nas plantas, a casca de arroz é indicada como componente principalmente em situações em que o produtor dispóe de materiais com alta densidade, ou para enraizamento de estacas.

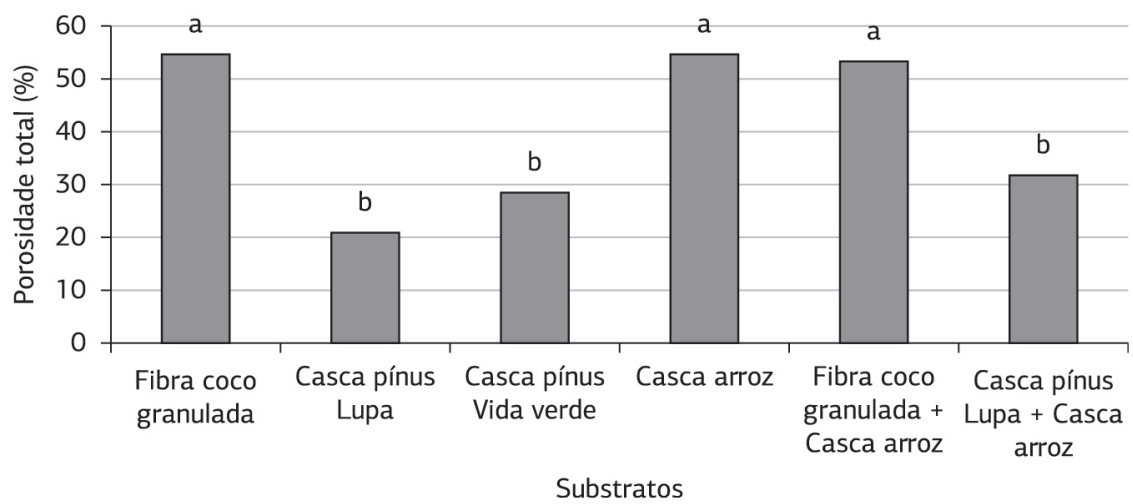

Figura 6. Porosidade de substratos calculada segundo a norma europeia. Letras minúsculas comparam substratos diferentes; mesmas letras não diferem entre si pelo teste de Tukey a 5\% de significância. 
Misturas de substratos resultam em propriedades físicas diferentes das dos materiais que lhes deram origem. A adição da casca de arroz à fibra de coco granulada em igual proporção náo é suficiente para alterar suas densidade volumétrica e porosidade, apesar de reduzir a retenção de água, mas pode ser uma opção interessante por diminuir os custos com os materiais. Na mistura com a casca de pínus Lupa, embora a casca de arroz aumente a quantidade de fraçôes maiores na mistura e reduza a elevada densidade volumétrica da casca de pínus pura, sua adição não é suficiente para alterar a baixa porosidade desse substrato. Deve haver cautela com a irrigaçáo, pois podem ocorrer problemas com as trocas gasosas, a movimentação de água e a drenagem.

\section{CONCLUSÃO}

Os métodos para a determinação dos atributos físicos produzem diferentes resultados para os atributos medidos. Isso reforça a necessidade de padronização para que as informaçóes sejam comparáveis: para determinação da umidade da amostra, secagem à temperatura de $65 \pm 5^{\circ} \mathrm{C}$; para granulometria, tempo de $10 \mathrm{~min}$ de agitação das peneiras; para densidade volumétrica, método da autocompactação; para capacidade de retençáo de água, utilização da base do anel volumétrico da amostra como referência e adoção da dupla saturação e da pré-tensão a $50 \mathrm{hPa}$; para determinação da curva de retenção de água dos substratos, os pontos de tensão em 10, 30, 50 e $100 \mathrm{hPa}$; para caracterização dos substratos quanto à sua origem, inclusão da densidade de partícula pela determinação da matéria orgânica e de cinzas.

A distribuição granulométrica uniforme das cascas de pínus aumenta a densidade volumétrica e diminui a porosidade mas mantém elevada sua capacidade de retenção de água.

A predominância de fraçôes granulométricas muito grandes, grandes e intermediárias na casca de arroz reduz a densidade volumétrica, eleva a porosidade e o espaço de aeração, diminuindo a retenção de água.

Das misturas de substratos estudadas, a adição da casca de arroz à fibra de coco granulada em igual proporção não é suficiente para alterar a densidade volumétrica e a porosidade, apesar de reduzir a retenção de água. $\mathrm{Na}$ mistura com a casca de pínus Lupa, sua adição não é suficiente para alterar a baixa porosidade desse substrato.

\section{AGRADECIMENTOS}

À Fundação de Amparo à Pesquisa do Estado de São Paulo (FAPESP), Coordenação de Aperfeiçoamento de Pessoal de Nível Superior (CAPES) e Fundação de Apoio à Pesquisa Agrícola (FUNDAG), pela concessão de bolsas, no curso de Pós-Graduação em Agricultura Tropical e Subtropical, no Instituto Agronômico (IAC).

\section{REFERÊNCIAS}

ABREU, M.F.; DIAS, R.S.; ABREU, C.A.; GONZALEZ, A.P. Reavaliação dos critérios constantes na legislação brasileira para análises de substratos. Bragantia, v.71, p.106-111, 2012. http://dx.doi. org/10.1590/S0006-87052012000100016

ALLAIRE, S.; CARON, J.; MÉNARD, C.; DORAIS, M. Growing media varying in particle size and shape for greenhouse tomato. Acta Horticulturae, v.644, p.307-311, 2004.

BAUMGARTEN, A. Methods of chemical and physical evaluation of substrates for plants. In: FURLANI, A.M.C. Caracterização, manejo e qualidade de substratos para produção de plantas. Campinas: Instituto Agronômico, 2002. p.7-15. (Documentos IAC, 70)

BERJÓN, M.A.; MURRAY, P.N. Sustratos para el cultivo sin suelo y fertirrigacion. In: CADAHIA, C. Fertirrigacion: cultivos hortícolas y ornamentales. Madrid: Mundi-Prensa, 1998. p.287-342.

BRASIL. Ministério da Agricultura, Pecuária e Abastecimento - MAPA. Secretaria de Apoio Rural e Cooperativismo. Instrução Normativa N. ${ }^{14}$, de 15 de dezembro de 2004. Aprova as Definiçóes e Normas sobre as Especificaçōes e as Garantias, as Tolerâncias, o Registro, a Embalagem e a Rotulagem dos Substratos para Plantas, constantes do anexo desta instrução normativa. Diário Oficial da República Federativa do Brasil, Brasília, DF, 17 dez. 2004. Seção 1, p.24.

BRASIL. Ministério da Agricultura, Pecuária e Abastecimento - MAPA. Secretaria de Defesa Agropecuária. Instrução Normativa No 17, de 21 de maio de 2007. Aprova os Métodos Analíticos Oficiais para Análise de Substratos e Condicionadores de Solos, na forma do Anexo à presente Instrução Normativa. Diário Oficial da República Federativa do Brasil, Brasília, DF, 24 maio 2007. Seção 1, p.8.

BRASIL. Ministério da Agricultura, Pecuária e Abastecimento - MAPA. Secretaria de Defesa Agropecuária. Instrução Normativa N.o 31, de 23 de outubro de 2008. Altera os subitens 3.1.2, 4.1 e 4.1.2, do Anexo à Instruçáo Normativa SDA n. ${ }^{\circ}$ 17, de 21 de maio de 2007. Diário Oficial da República Federativa do Brasil, Brasília, DF, 24 out. 2008. Seção 1, p.20.

BURÉS, S. Sustratos. Madrid: Ediciones Agrotécnicas, 1997. 341p.

CADAHIA, C. Fertirrigacion: cultivos hortícolas y ornamentales. Madrid: Mundi-Prensa, 1998. 475p.

CARDOSO, A.F.; CHARLO, H.C.O.; ITO, L.A.; CORÁ, J.E.; BRAZ, L.T. Caracterização física do substrato reutilizado da fibra da casca de coco. Horticultura Brasileira, v.28, p.385-392, 2010.

COMITÉ EUROPEÉN DE NORMALISATION - CEN. Norma EN 13039. Mejoradores de suelo y sustratos de cultivo - Determinación del contenido en materia orgánica y de las cenizas. Bruxelles: Comité Europeén de Normalisation, 1999a.

COMITÉ EUROPEÉN DE NORMALISATION - CEN. Norma EN 13040. Mejoradores de suelo y sustratos de cultivo - Preparación de muestras para ensayos químicos e físicos, determinación del contenido de materia seca, contenido de humedad y de la densidad aparente compactada en laboratorio. Bruxelles: Comité Europeén de Normalisation, 1999b.

COMITÉ EUROPEÉN DE NORMALISATION - CEN. Norma EN 13041. Mejoradores de suelo y sustratos de cultivo - Determinación 
de las propiedades físicas. Densidad aparente seca, volumen de aire, volumen de agua, valor de contracción y porosidad total. Bruxelles: Comité Europeén de Normalisation, 1999c.

DAUDT, R.H.S.; GRUSZYNSKI, C.; KÄMPF, A.N. Uso de resíduos de couro wet-blue como componente de substrato para plantas. Ciência Rural, v.37, p.91-96, 2007. http://dx.doi.org/10.1590/ S0103-84782007000100015

DE BOODT, M.; VERDONCK, O. The physical properties of the substrates in horticulture. Acta Horticulturae, v.26, p.37-44, 1972.

DE KREIJ, C.; VAN ELDEREN, C.W.; WEVER, G.; DUIJVESTIJN, R.C.M. Extraction of growing media regarding its water holding capacity and bulk density. Acta Horticulturae, v.548, p.409-414, 2001.

FERMINO, H.; KÄMPF, A. Considerations about the packing density of growing media prepared under increasing levels of humidity. Acta Horticulturae, v.697, p.147-151, 2005.

FERMINO, M.H.; GONÇALVES, R.S.; BATTISTIN, A.; SILVEIRA, J.R.P.; BUSNELLO, A.C.; TREVISAN, M. Aproveitamento dos resíduos da produçáo de conserva de palmito como substrato para plantas. Horticultura Brasileira, v.28, p.282-286, 2010. http://dx.doi. org/10.1590/S0102-05362010000300007

FERMINO, M.H.; KÄMPF, A.N. Densidade de substratos dependendo dos métodos de análise e níveis de umidade. Horticultura Brasileira, v.30, p.75-79, 2012. http://dx.doi.org/10.1590/S0102-05362012000100013

FERMINO, M.H.; KÄMPF, A.N. Impedância mecânica de substratos para plantas submetidos a diferentes tensóes hídricas. Pesquisa Agropecuária Gaúcha, v.12, p.25-30, 2006.

FERNANDES, C.; CORÁ, J.E.; BRAZ, L.T. Desempenho de substratos no cultivo do tomateiro do grupo cereja. Horticultura Brasileira, v.24, p.42-46, 2006. http://dx.doi.org/10.1590/S010205362006000100009

FERNANDES, C.; CORÁ, J.E.; BRAZ, L.T. Reuse of sand, crushed sugarcane and peanut hull-based substrates for cherry tomato cultivation. Scientia Agricola, v.64, p.630-635, 2007. http://dx.doi.org/10.1590/ S0103-90162007000600011

HOFFMANN, G. Verbindliche Methodenzur Untersuchung von TKS und Gartnerischen Erden. VDLUFA-Mitteilungen, v.6, p.129153, 1970.

MARTINEZ, P.F. Manejo de substratos para horticultura. In: FURLANI, A.M.C. Caracterização, manejo e qualidade de substratos para produçáo de plantas. Campinas: Instituto Agronômico, 2002. p.53-73. (Documentos IAC, 70)

MINER, J.A. Sustratos: propiedades y caracterización. Madrid: Mundi-Prensa, 1994. 172p.
MOTA, L.C.; VAN MEETEREN, U.; BLOK, C. Comparison of the physical properties of vermicompost from paper mill sludge and green compost as substitutes for peat base growing media. Acta Horticulturae, v.819, p.78-84, 2007.

NEMATI, M.R.; FORTIN, J.P.; LUSSIER, M.C.; PRINCE, M.J. Development of a rapid and accurate determination of particle size distribution in organic substrates. Acta Horticulturae, v.819, p.297302, 2009 .

PAGLIARINI, M.K.; CASTILHO, R.M.M.; ALVES, M.C. Caracterização físico-química de misturas de componentes de substrato com resíduo de celulose para fins de produção de mudas. Revista Brasileira de Agroecologia, v.7, p.160-169, 2012.

ROWELL, D.L. Soil science: methods and applications. New York: Longman Group, 1994. 350p.

SOUZA JÚNIOR, J.O.; CARMELLO, Q.A.C.; SODRÉ, G.A. Substrato e adubação fosfatada para a produção de mudas clonais de cacau. Revista Brasileira de Ciência do Solo, v.35, p.151-159, 2011. http://dx.doi.org/10.1590/S0100-06832011000100014

TEDESCO, M.J.; VOLWEISS, S.J.; BOHNEN, H. Análises de solo, plantas e outros materiais. Porto Alegre: Universidade Federal do Rio Grande do Sul, Faculdade de Agronomia, Departamento Solos, 1985. 188p. (Boletim Técnico, 5)

TERÉS, V.; ARTETXE, A.; BEUNZA, A.; SAINZ DE LA MAZA, E.; LEUZAUN, M. Physical properties of the substrates. Acta Horticulturae, v.559, p.663-668, 2001.

VALERO, R.M.M.; MATSURA, E.E.; SOUZA, A.L. Caracterização física de dois substratos orgânicos para plantas e a estimativa da umidade por meio da reflectometria no domínio do tempo. Ciência Rural, v.39, p.571-574, 2009. http://dx.doi.org/10.1590/S010384782009000200042

VENCE, L.B. Disponibilidad de agua-aire en sustratos para plantas. Ciencia del Suelo, v.26, p.105-114, 2008.

VERDONCK, O; DEMEYER, P. The influence of the particle size on the physical properties of growing media. Acta Horticulturae, v.644, p.99-101, 2004.

VIEIRA, M.A.; PAULETTO, E.A. Avaliação de atributos físicos do substrato de casca de arroz (oryza sativa l.) carbonizada e tratada com polímeros hidrofílicos sintéticos. Bioscience Journal, v.25, p.1-6, 2009.

WEVER, G; VAN WINKEL, A. Interlaboratory study CEN-Methods for the analysis of growing media and soil improvers. Acta Horticulturae, v.644, p.597-601, 2004. 